\title{
Surgical treatment for mediastinal parathyroid adenoma causing primary hyperparathyroidism
}

\author{
Masahiro Kitada*, Shunsuke Yasuda, Takahashi Nana, Kei Ishibashi, Satoshi Hayashi and Satoru Okazaki
}

\begin{abstract}
Background: Primary hyperparathyroidism is a rare disease characterized by excessive secretion of parathyroid hormone from parathyroid adenoma, hyperplasia, or malignancy. The clinical symptoms of the condition are those of hypercalcemia. Although the lesions are commonly located in the neck region, in about 1-2 \% of cases, the lesions are ectopically located within the mediastinum, where surgical excision using the cervical approach is difficult. The principal treatment of the condition is surgical excision of the lesion. However, some patients require additional surgery because of recurrence due to intraoperative dissemination. Therefore, safe and accurate excision is essential for the treatment. We reviewed the surgical treatment used at our institution for mediastinal parathyroid adenoma that caused primary hyperparathyroidism.
\end{abstract}

Method: The subjects were four patients with primary hyperparathyroidism due to mediastinal parathyroid adenoma who underwent surgery at our institution within a period of 10 years, between January 2005 and December 2014. All of the patients were female, with a mean age of 64.5 years (range, 55-74 years). The examined variables included background factors, clinical condition, surgical method, and clinical outcome.

Result: In all of the patients, primary hyperparathyroidism was detected with symptoms of hypercalcemia. Laboratory tests revealed a mean serum calcium level of $11.85 \mathrm{mg} / \mathrm{dL}$ (range, 11.2-13.2 mg/dL) and a mean parathyroid hormone (intact PTH) level of $304.8 \mathrm{pg} / \mathrm{mL}$ (range, 126-586 pg/mL), indicating elevated levels for all patients. Chest computed tomography (CT) revealed tumors with a mean diameter of $2.8 \mathrm{~cm}$ (range, 10-45 mm) in the anterior mediastinum in all of the patients. On 99mTC-methoxy isobutyl isonitrile (MIBI) scintigraphy, abnormal accumulation was observed in all of the patients. Regarding the surgical methods, median sternotomy was used for three cases and upper partial sternotomy was used for one case. The surgery was safely and accurately performed, without postoperative complications. After surgery, the serum calcium levels immediately returned to normal and the symptoms improved.

Conclusion: We performed excision safely and accurately in all of the patients. In tumor identification, $99 \mathrm{mTC}-\mathrm{MIBI}$ scintigraphy was useful. Accurate tumor identification and selection of the optimal surgical method are important for prevention of recurrence due to intraoperative dissemination.

\footnotetext{
* Correspondence: k1111@asahikawa-med.ac.jp

Department of Breast Disease Center, Asahikawa Medical University,

Midorigaoka-Higashi 2-1-1-1, Asahikawa, Hokkaido 078-8510, Japan
} 


\section{Background}

Primary hyperparathyroidism is a disease with various symptoms related to hypercalcemia due to excessive secretion of parathyroid hormone from a tumor or hyperplasia, such as adenoma and carcinoma, which arises in the parathyroid. The principal treatment of the condition is surgical excision of the pathological tissue. Although most parathyroid adenomas are located in the neck region, 11-25\% of them are located within the mediastinum and 1-2\% are located in the mediastinum, where surgical excision using the cervical approach is difficult [1-3]. We experienced surgical treatment of a mediastinal parathyroid adenoma that caused primary hyperparathyroidism in four patients.

\section{Method}

The subjects were four patients with primary hyperparathyroidism due to mediastinal parathyroid adenoma who underwent surgery at our institution within a period of 10 years, between January 2005 and December 2014. All of the patients were female, with a mean age of 64.5 years (range, 55-74 years). The examined variables included background factors, symptoms at the time of diagnosis, clinical condition, surgical method, and clinical outcome.

\section{Result}

The clinical symptoms of and surgical methods used for all the patients are shown in Table 1. In all of the patients, primary hyperparathyroidism was detected with the following symptoms of hypercalcemia: two patients presented with weakness, including muscle strength reduction; one presented with urinary calculus; and the remaining patient presented with digestive symptoms such as nausea and abdominal pain. Laboratory tests showed a mean serum calcium level of $11.85 \mathrm{mg} / \mathrm{dL}$ (range, $11.2-13.2 \mathrm{mg} / \mathrm{dL}$ ) and a mean intact PTH level of $304.8 \mathrm{pg} / \mathrm{mL}$ (range, 126-586 pg/mL), indicating elevated levels in all of the patients. Chest CT revealed tumors with a mean diameter of $2.8 \mathrm{~cm}$ (range, 10-45 mm) in the anterior mediastinum in all of the patients. One patient had a cystic tumor (case 3; Fig. 1). On 99mTCMIBI scintigraphy, abnormal accumulation was observed in all of the patients (Fig. 2). Regarding the surgical methods, median sternotomy was used for cases 1, 2, and 3, and upper partial sternotomy was used for case 4. The surgery was safely and accurately performed. After surgery, the serum calcium levels immediately returned to normal, and the symptoms improved without recurrence. According to histological examination results, three patients were diagnosed with parathyroid adenoma and the remaining patient was diagnosed with parathyroid hyperplasia. None of the patients had any malignancy. Among the three patients with adenoma, one had a cystic mass.

\section{Discussion}

Most cases of primary hyperparathyroidism are caused by excessive secretion of intact PTH from parathyroid adenoma or parathyroid hyperplasia. About $90 \%$ of patients are women. The mean age of the patients is reportedly around 60 years. The disease is usually detected with symptoms of hypercalcemia, including urinary calculus, bone lesion (osteoporosis), polyposia and polyuria, general malaise, vomiting, and constipation. Recently, in a number of patients, the disease has been detected incidentally during routine medical checkup, according to laboratory test results that show hypercalcemia, even without typical clinical symptoms. The condition can occur as a part of multiple endocrine neoplasia type 1 (MEN1), which consists of primary hyperparathyroidism, gastroenteropancreatic neuroendocrine tumor, and pituitary adenoma $[4,5]$. Most parathyroid adenomas are located in the neck region and mediastinum. In particular, 11-25 \% of parathyroid adenomas are located within the mediastinum, of which about $2 \%$ are difficult to excise by using the cervical approach [1-3]. In addition, mediastinal parathyroid adenomas are frequently small; therefore, accurate localization is essential [6]. In addition, 99TC-MIBI scintigraphy is useful

Table 1 Characteristics of patients with hyperthyroidism in whom mediastinal lesions and surgical approach, pathology, clinical outcome

\begin{tabular}{|c|c|c|c|c|}
\hline Case & 1 & 2 & 3 & 4 \\
\hline Age & 57 & 72 & 74 & 55 \\
\hline Gender & women & women & women & women \\
\hline Chief complaint & nephrolithiasis & listlessness & listlessness & abdominal pain feel nausea \\
\hline Serum calcium level (mg/dl) & 11.1 & 11.2 & 13.2 & 11.9 \\
\hline intact-PTH (pg/dl) & 126 & 353 & 586 & 154 \\
\hline Location & anterior mediastinum & anterior mediastinum & anterior mediastinum & anterior mediastinum \\
\hline Surgical approach & Total sternotomy & Total sternotomy & Total sternotomy & Partial sternotomy \\
\hline Pathology & adenoma & adenoma & adenoma & hyperplasia \\
\hline Post operative hyperthyroidism & cured & cured & cured & cured \\
\hline
\end{tabular}



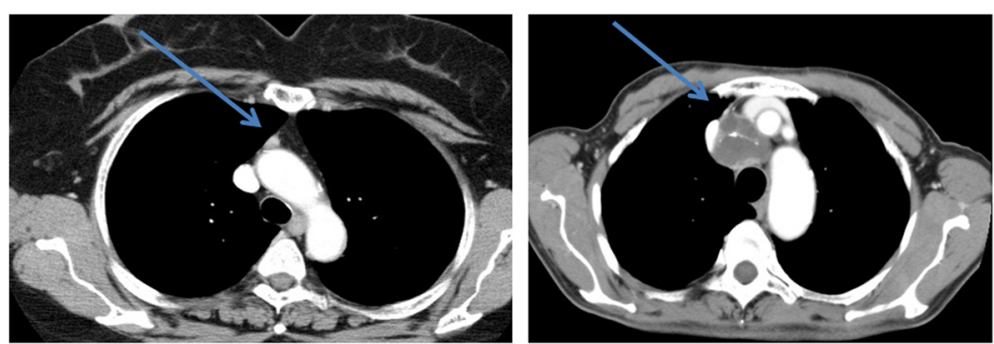

Case1

Case2
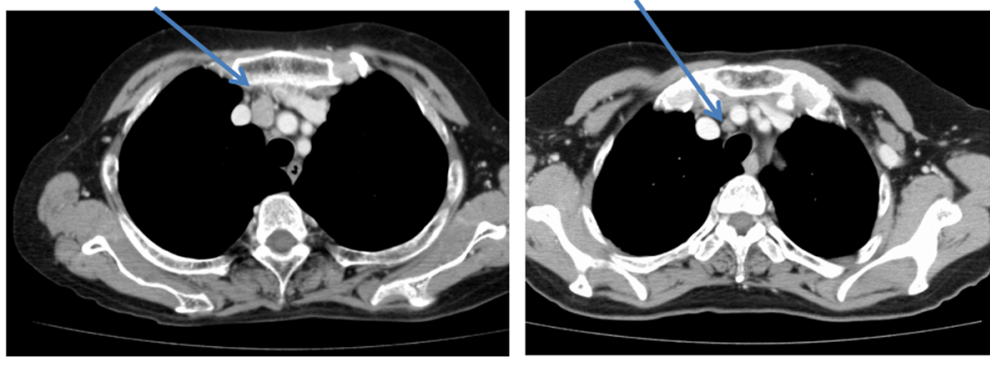

Case3

Case4

Fig. 1 Computerized tomography. Mediastinum parathyroid adenoma or hyperplasia legion (arrow)

for localization of the tumor and therefore essential for preoperative diagnosis [1,7]. Previous studies also reported the usefulness of longitudinal vein harvesting $[8,9]$ and monitoring of serum PTH (intraoperative PTH) levels [10].

While a study reported a successful treatment of the condition with percutaneous ethanol injection, [11] most cases require tumor excision. Conventionally, median sternotomy has been used for surgical excision of mediastinal parathyroid adenomas that are difficult to excise using the cervical approach. This method has advantages of accuracy in tumor identification and good operative view. However, given that most of the tumors are benign, less-invasive approaches have gained popularity. In addition to cases of upper partial sternotomy, cases of thoracoscopic excision [12, 13] and excision through parasternal intercostal incision have been reported [14]. Therefore, selection of the optimal surgical approach for each patient is important for accurate tumor identification and excision.

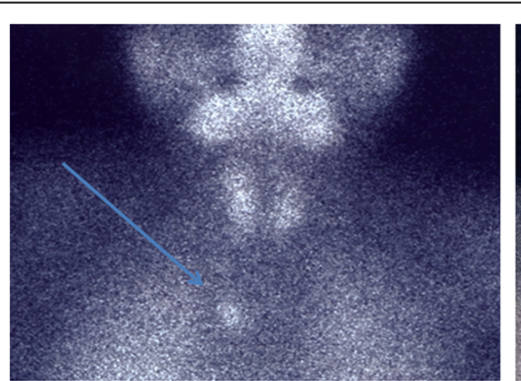

Case1

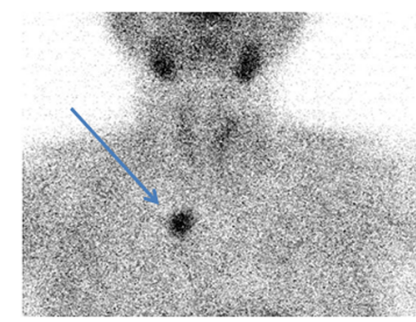

Case3

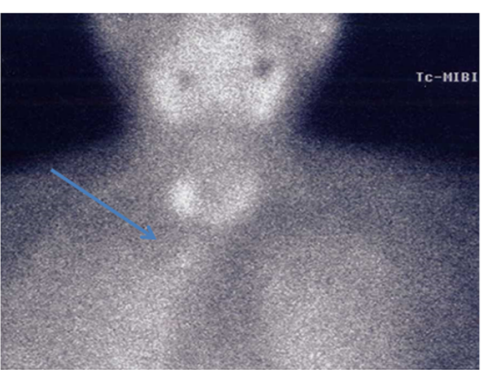

Case2

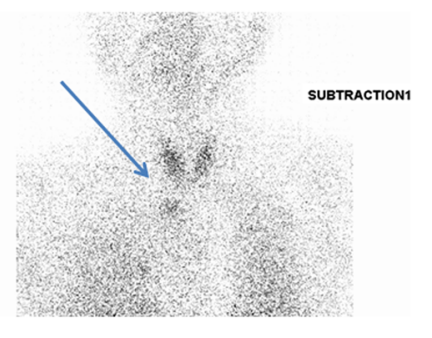

Case4

Fig. 2 99mTc MIBI scan. Mediastinum parathyroid adenoma or hyperplasia lesion (arrow). Image of case3 and 4 are subtraction image 


\section{Conclusion}

We reviewed the surgical treatment used in our institution for four cases of ectopic mediastinal parathyroid adenoma that caused primary hyperparathyroidism. Accurate tumor identification and selection of the optimal surgical method are important for prevention of recurrence due to intraoperative dissemination.

\section{Consent}

Informed consent was obtained from each patient for publication. A copy of the written consent is available for review by the Editor-in Chief of this journal

\section{Competing interests}

The authors declare that they have no competing interests.

\section{Authors' contribution}

MK have operated this case and analyzed all data. SY and NT, KI, SH, SO did the assistant of the operation. All authors read and approved the final manuscript.

\section{Acknowledgements}

The authors declare that they have no competing interests.

Received: 26 May 2015 Accepted: 5 April 2016

Published online: 07 April 2016

\section{References}

1. Ogawa T, Tsuji E, Kanauchi H, Yamada K, Mimura Y, Kaminishi M.

Excision of postesophageal parathyroid adenoma in posterior mediastinum with intraoperative $99 \mathrm{mTechnetium} \mathrm{sestamibi} \mathrm{scanning}$ Ann Thorac Surg. 2007;84(5):1754-6.

2. Medrano C, Hazelrigg SR, Landreneau RJ, Boley TM, Shawgo T, Grasch A. Thoracoscopic resection of ectopic parathyroid glands. Ann Thorac Surg. 2000;69(1):221-3.

3. Abbas F, Biyabani SR, Memon A, Talati J. Mediastinal parathyroid adenoma causing primary hyperparathyroidism. J Pak Med Assoc. 2007;57(2):93-5.

4. Lo CY, Kung AW, Lam KS. Surgical treatment for primary hyperparathyroidism. Chin Med J (Engl). 1997;110(8):612-6.

5. Lassen T, Friis-Hansen L, Rasmussen AK, Knigge U, Feldt-Rasmussen U Primary hyperparathyroidism in young people. When should we perform genetic testing for multiple endocrine neoplasia 1 (MEN-1)? J Clin Endocrinol Metab. 2014;99(11):3983-7.

6. Ng P, Lenzo NP, McCarthy MC, Thompson I, Leedman PJ. Ectopic parathyroid adenoma localised with sestamibi SPECT and image-fused computed tomography. Med J Aust. 2003;179(9):485-7.

7. Krausz Y, Bettman L, Guralnik L, Yosilevsky G, Keidar Z, Bar-Shalom R, Even-Sapir E, Chisin R, Israel O. Technetium-99 m-MIBI SPECT/CT in primary hyperparathyroidism.

World J Surg. 2006;30(1):76-83.

8. Gough I. Reoperative parathyroid surgery: the importance of ectopic location and multigland disease. ANZ J Surg. 2006;76(12):1048-50.

9. Moriyama T, Kageyama K, Nigawara T, Koyanagi M, Fukuda I, Yashiro H, Suda T. Diagnosis of a case of ectopic parathyroid adenoma on the early image of 99mTc-MIBI scintigram. Endocr J. 2007:54(3):43740. Epub 2007 Apr 25

10. Sagan D, Goździuk K. Surgical treatment of mediastinal parathyroid adenoma: rationale for intraoperative parathyroid hormone monitoring Ann Thorac Surg. 2010;89(6):1750-5.

11. Singh Ospina N, Thompson GB, Lee RA, Reading CC, Young Jr WF. Safety and efficacy of percutaneous parathyroid ethanol ablation in patients with recurrent primary hyperparathyroidism and multiple endocrine neoplasia type 1. J Clin Endocrinol Metab. 2015;100(1):87-90.

12. Dinçer SI, Demir A, Kara HV, Günlüoglu MZ. Thoracoscopic removal of a maternal mediastinal ectopic parathyroid adenoma causing neonatal hypocalcemia: a case report. Ann Thorac Cardiovasc Surg. 2008;14(5):325-8.
13. Chae AW, Perricone A, Brumund KT, Bouvet M. Outpatient videoassisted thoracoscopic surgery (VATS) for ectopic mediastinal parathyroid adenoma: a case report and review of the literature. $J$ Laparoendosc Adv Surg Tech A. 2008;18(3):383-90.

14. Liman ST, Topcu S, Dervisoglu E, Gorur GD, Elicora A, Burc K, Akgul AG. Excision of ectopic mediastinal parathyroid adenoma via parasternal videomediastinoscopy. Ann Thorac Cardiovasc Surg. 2014;20(1):67-9.
Submit your next manuscript to BioMed Central and we will help you at every step:

- We accept pre-submission inquiries

- Our selector tool helps you to find the most relevant journal

- We provide round the clock customer support

- Convenient online submission

- Thorough peer review

- Inclusion in PubMed and all major indexing services

- Maximum visibility for your research

Submit your manuscript at www.biomedcentral.com/submit 